\title{
ANALISIS PERHITUNGAN BAGI HASIL MUDHARABAH TABUNGAN PADA (STUDI KASUS) PT. BANK PEMBIAYAAN RAKYAT SYARIAH (BPRS)HARTA INSAN KARIMAH (HIK) MAKASSAR
}

\author{
Muhadjir Suni*
}

\begin{abstract}
This research is a qualitative descriptive study. by collecting descriptive data as outlined in the form of reports and descriptions. Data is obtained by approaching or documenting archives, documents, records or everything needed for this research. Then the data will be analyzed with qualitative analysis. The data that has been obtained will be validated by using the triangulation method, which is checking data from various sources in various ways, and at various times. There are two triangulation techniques namely source triangulation and technical triangulation. The results of the research conducted at BPRS HIK Makassar showed the mechanism for calculating the profit sharing system used using system revenue sharing with a ratio of 70:30. The revenue sharing system applies to the bank income that will be distributed calculated based on gross income. In BPRS HIK Makassar the Revenue sharing system mechanism is used by way of sharing the benefits of fund management carried out by the Bank before deducting operational costs or profit sharing calculated from gross profit / total income and using mudharabah mutlaqah and mudharabah muqayyadah contracts. So the revenue sharing system at BPRS HIK Makassar is in accordance with the National Shari'ah Council fatwa No: 02/DSNMUI/IV/2000 regarding the general provisions of savings based on Mudharabah.
\end{abstract}

Keywords: Calculation of Profit Sharing, Syari'ah, Mudharabah savings.

*) Prodi. Pengelolaan dan Manajemen Parawisata, Politeknik Pariwisata Negeri Makassar

E-mail: muhadjirsuni@yahoo.com 


\section{PENDAHULUAN}

Berdasarkan operasinya dikenal beberapa produk bank syariah antara lain produk dengan prinsip mudharabah dan musyarakah. Transaksi jasa penyimpanan dana di perbankan syariah dilakukan atas dasar akad (kontrak perikatan). Dalam produk tabungan di perbankan syariah biasanya ada dua bentuk pilihan tabungan, tabungan dengan akad mudharabah dan tabungan dengan akad wadiah. Secara teknis mudharabah adalah akad kerja sama usaha antara dua pihak dimana pihak pertama (shahibul maal) menyediakan seluruh modal, sedangkan pihak lainnya menjadi pengelola (Al Arif, 2012). Bentuk ini menegaskan kerja sama dalam paduan kontribusi $100 \%$ modal kas dari shahibul maal dan keahlian dari mudharib dengan nisbah bagi hasil menurut kesepakatan dimuka. Perjanjian mudharabah dapat juga dilakukan antara beberapa penyedia dana dan pelaku usaha. Jika usaha mengalami kerugian, maka seluruh kerugian ditanggung oleh pemilik dana, kecuali jika ditemukan adanya kelalaian atau kesalahan oleh pengelola dana, seperti penyelewengan, kecurangan, dan penyalahgunaan dana. Keuntungan usaha secara mudharabah dibagi menurut kesepakatan yang dituangkan dalam kontrak, sedangkan apabila rugi ditanggung oleh pemilik modal selama kerugian itu bukan akibat kelalaian si pengelola.

Dalam penulisan ini, penulis akan memilih lokasi penelitian di PT. Bank Pembiayaan Rakyat Syariah Makassar Harta Insan Karimah (BPRS HIK). BPRS HIK sebagai Bank yang berbeda dengan bank-bank pada umumnya yang hanya dimiliki oleh segelintir orang, pemegang saham BPRS HIK relatif banyak tujuan dari BPRS untuk menjalankan kegiatan usaha perbankan sesuai prinsip syariah guna mendukung perkembangan kota Makassar khususnya. Penulis akan menganalisis bagaimana sistem transaksi tabungan Mudharabah di BPRS HIK Makassar sesuai dengan akad mudharabah mutlaqah dan mudharabah muqqayadah dan sistem bagi hasil yang diterapkan di BPRS HIK Makassar pada tabungan Mudharabah adalah pada acuan prinsip revenue sharing.

Bank merupakan lembaga keuangan yang usaha pokoknya memberikan kredit dan jasa-jasa dalam lalu lintas pembayaran dan peredaran uang. Berdasarkan undang-undang perbankan No. 10 tahun 
1998: "Bank adalah badan usaha yang menghimpun dana dari masyarakat dalam bentuk simpanan dan menyalurkannya kepada masyarakat dalam bentuk kredit dan atau bentuk-bentuk lainnya dalam rangka mneingkatkan taraf hidup rakyat banyak". Tiap Negara Bank bukanlah hal yang asing.

Berikut fungsi utama Bank : Menghimpun dana dari masyarakat, Menyalurkan Dana Kepada Masyarakat

Bank syariah di Indonesia lahir sejak 1992. Bank syariah pertama di Indonesia adalah Bank Muamalat Indonesia. Namun sejak adanya krisis moneter yang melanda Indonesia pada 1997 dan 1998, kemudian dikonversi menjadi bank syariah mandiri, bank syariah kedua di Indonesia. Pada dasarnya Bank syariah memiliki sistem operasional yang berbeda dengan konvensional. Bank syariah memberikan layanan bebas bunga kepada para nasabahnya. Fungsi Bank Syariah : Manajer Investasi, Investor, Jasa Keuangan, Fungsi Sosial.

Sistem bagi hasil merupakan sistem dimana dilakukannya perjanjian atau ikatan bersama didalam melakukan kegiatan usaha. Besarnya penentuan porsi bagi hasil antara kedua belah pihak ditentukan sesuai kesepakatan bersama, dan harus terjadi dengan adanya kerelaan (An-Tarodhin) di masing-masing pihak tanpa adanya unsure paksaan sesuai 2 sistem mekanisme yaitu Profit Sharing, dan Revenue Sharing.

Modal dalam pembiayaan ini $100 \%$ dari pemilik modal, sedangkan keahlian dan cara mengelolanya dari pengelola modal. Berikut landan yuridis Mudharabah::

QS. AL-Muzammil [73]:20

"......dan dari orang orang yang berjalan di muka bumi mencari sebagian karunia Allah SWT..." (QS. Al-Muzammil:20).

Ayat diatas menjelaskan bahwa dalam mencari karunia Tuhan dengan cara jual beli dengan cara sistem mudharabah, karena mudharabah adalah salah satu jenis jual beli yang telah dianjurkan oleh Rasulullah. Mudharabah terbagi menjadi dua jenis yakni Mudharabah mutlaqah, dan Mudharabah muqayyadah.

Ada beberapa poin perhitungan bagi hasil tabungan Mudharabah. Adapun poin-poin tersebut adalah saldo rata-rata harian 
dan pendapatan yang akan dibagi hasilkan, Muhammad (2005: 117-120). Dengan melihat penjelasan di atas, yaitu tentang proses perhitungan bagi hasil dan contoh kasus bagi hasil, maka perhitungan bagi hasil dapat dirumuskan sebagai berikut:

Bagi Hasil $=\frac{\text { Keuntungan } X \text { Nisbah } X \text { Saldo rata }- \text { rata dana di Bank }}{\text { Saldo } \text { rata }- \text { rata } \text { Tabungan Harian }} \ldots$ (1)

\section{METODE PENELITIAN}

Metode yang di gunakan dalam penelitian ini deskriptif dengan metode pendekatan metode Kualitatif dengan menganalisis dan mengumpulkan data. Jenis data yang digunakan dalam penelitian ini adalah data kualitatif berdasarkan dua sumber yaitu sumber data primer dan data sekunder.. Data primer dalam penelitian ini diperoleh melalui observasi dan wawancara kepada pihak Bank Pembiayaan Rakyat Syariah (BPRS) HIK Makassar, yang memahami langsung tentang perhitungan bagi hasil Mudharabah tabungan atau deposito. Sedangkan, data sekunder Menurut Marzuki (1986:56) adalah “data yang bukan diusahakan sendiri pengumpulannya oleh peneliti". Data sekunder pada penelitian ini meliputi: sejarah perusahaan, lokasi, dan juga data-data lain yang diperlukan untuk penelitian ini.

Data ini dapat diambil dengan cara melakukan pendekatan atau dokumentasi terhadap arsip, dokumen, catatan atau segala sesuatu yang dibutuhkan untuk penelitian ini. Kemudian data akan dianalisis dengan analsis kualitatif. Adapum langkah-langkah yang dilakukan setelah memperoleh data adalah sebagai berikut:

1. Mendiskripsikan secara umum PT.Bank Pembiayaan Rakyat Syariah (BPRS) HIK Makassar.

2. Mendiskripsikan dan menganalisis sistem perhitungan bagi hasil pada produk Tabungan Mudharabah.

Data yang telah diperoleh akan divalidasi dengan menggunakan metode triangulasi, yaitu pengecekan data dari berbagai sumber dengan berbagai cara, dan berbagai waktu (Sugiyono, 2014). Ada dua teknik triangulasi yakni triangulasi sumber dan triangulasi teknik. 


\section{HASIL DAN PEMBAHASAN}

\section{Sistem Bagi Hasil Tabungan Mudharabah}

Berdasarkan hasil wawancara yang dilakukan dengan karyawan BPRS HIK Makassar bahwa konsep bank syariah dapat digambarkan sebagai berikut:

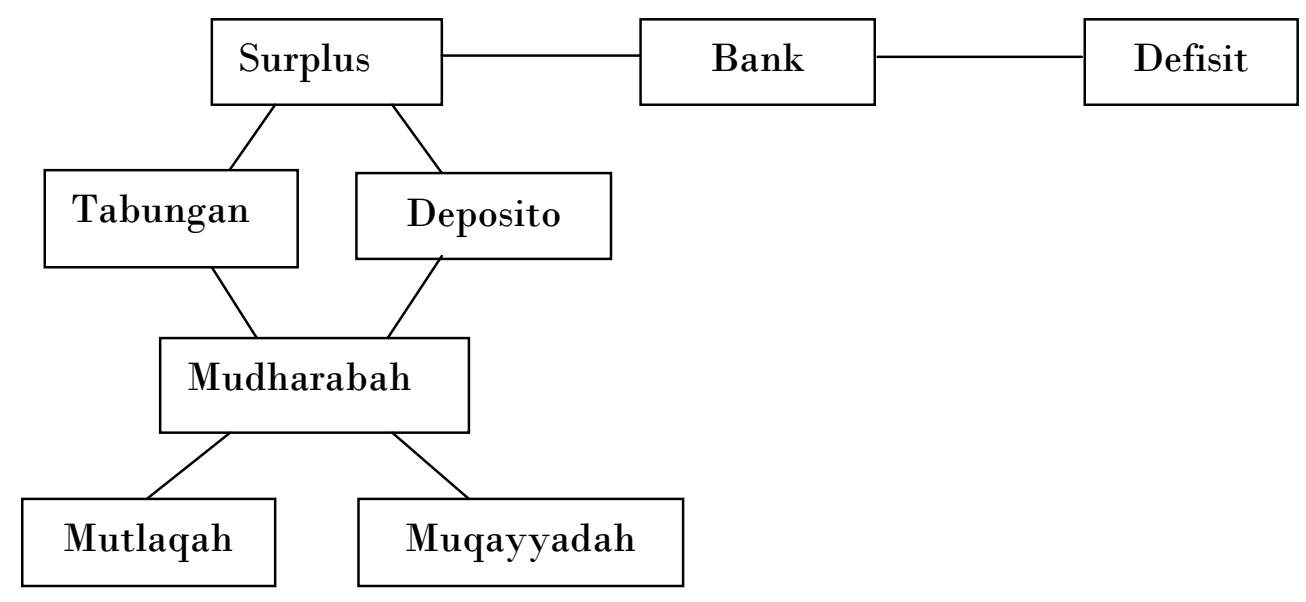

Gambar 1. Bagi Hasil Tabungan Mudharabah

Berdasarkan hasil wawancara dan pengamatan, sistem bagi hasil tabungan mudharabah yang diterapkan oleh BPRS HIK Makassar adalah sistem Revenue sharing. Sistem ini mempunyai pengertian bahwa adanya pembagian hasil, penghasilan atau pendapatan antara shahibul maal (nasabah) dengan mudharib (BPRS HIK Makassar). Dan jika pihak bank mengalami kerugian maka kerugian tersebut ditanggung oleh kedua belah pihak yaitu nasabah dan BPRS HIK Makassar. Dalam pembagian hasil, BPRS HIK Makassar mempunyai standar nominal tabungan untuk setiap nasabah, yaitu minimal mempunyai tabungan Rp.50.000.-.

Proses Perhitungan Bagi Hasil.

Dalam perhitungan bagi hasil, langkah-langkah awal dalam penentuan bagi hasil adalah: 
1) Penetapan Nisbah bagi hasil untuk tabungan Mudharabah sebesar $30 \%: 70 \%$, jadi $30 \%$ untuk shahibul maal (nasabah) dan 70\% untuk mudharib (BPRS HIK Makassar).

2) Menghitung saldo rata-rata tabungan masing-masing nasabah. Adapun contoh perhitungannya sebagai berikut:

Tabel 1. Saldo rata-rata tabungan nasabah

\begin{tabular}{|c|c|c|c|c|}
\hline \multirow{2}{*}{ Tangga } & \multirow{2}{*}{$\begin{array}{l}\text { Keteranga } \\
\mathbf{n}\end{array}$} & \multicolumn{3}{|l|}{ Mutasi } \\
\hline & & D & $\mathbf{K}$ & $\mathrm{S}$ \\
\hline $\begin{array}{l}1 / 5- \\
2017\end{array}$ & Tabungan & - & $\begin{array}{l}\text { Rp.1.000.00 } \\
0\end{array}$ & $\begin{array}{l}\text { Rp. } 1.000 .00 \\
0\end{array}$ \\
\hline $\begin{array}{l}10 / 5- \\
2017\end{array}$ & Transfer & - & $\begin{array}{l}\text { Rp.1.000.00 } \\
0\end{array}$ & $\begin{array}{l}\text { Rp.2.000.00 } \\
0\end{array}$ \\
\hline $\begin{array}{l}15 / 5- \\
2017\end{array}$ & Tarik tunai & $\begin{array}{l}\text { Rp.500.00 } \\
0\end{array}$ & - & $\begin{array}{l}\text { Rp.1.500.00 } \\
0\end{array}$ \\
\hline $\begin{array}{l}20 / 5- \\
2017\end{array}$ & Tabungan & - & $\begin{array}{l}\text { Rp.1.000.00 } \\
0\end{array}$ & $\begin{array}{l}\text { Rp.2.500.00 } \\
0\end{array}$ \\
\hline $\begin{array}{l}30 / 5- \\
2017\end{array}$ & $\mathrm{BH}$ & & 7.725 & \\
\hline $\begin{array}{l}31 / 2- \\
2017\end{array}$ & PPH & 7.725 & & \\
\hline
\end{tabular}

Pada bulan Mei 2017 bagi hasil tabungan yang diterima BPRS HIK Makassar sebesar Rp. 7.000.000 dan saldo rata-rata tabungan yang terkumpul pada bulan tersebut sebesar Rp. 1.500 .000 sementara jumlah BHS yang di pungut dari hasil operasional BPRS HIK Makassar sebesar Rp 25.750.000 dengan pagu 30:70 berdasarkan perhitungan bagi hasil data tersebut diatas diperoleh sebesar.

$25.750 .00 \times 30 \%=7.725 .000($ HB untuk $)$

$7.725 .000 / 1.500 .000 \times 100 \%=0,515 \%$

Bagi Hasil yang diperoleh sebesar Rp 1.500.000 X 0,515\%=Rp.7.725 
Faktor yang mempengaruhi bagi hasil tabungan mudharabah adalah jumlah dana yang tersedia untuk diinvestasikan/didepositokan. Dengan demikian, di BPRS HIK Makassar dalam perhitungan prosentase bagi hasil juga mempertimbangkan jangka waktu transaksi tabungan. Nisbah pada tabungan Mudharabah kurang mempengaruhi terhadap prosentase bagi hasil, karena nisbah antara BPRS HIK Makassar dengan nasabah adalah 70:30, akan tetapi keuntungan dalam tabungan mudharabah disini adalah pembebasan dalam segi administrasi dalam perhitungan bagi hasil.

Dari hasil wawancara dengan karyawan BPRS HIK Makassar dalam bagi hasil yang telah disepakati dalam akad tabungan Mudharabah yaitu sebesar 70\% untuk BPRS HIK Makassar dan 30\% untuk nasabah. Dari keseluruhan aspek-aspek dalam tabungan mudharabah di BPRS HIK Makassar, dapat terlihat dalam tabel dibawah ini

Tabel 2. Aspek-aspek dalam tabungan mudharabah di BPRS HIK Makassar

\begin{tabular}{|l|l|}
\hline \multicolumn{1}{|c|}{ Aspek } & \multicolumn{1}{c|}{ Tabungan } \\
\hline 1. Transaksi & \multicolumn{1}{c|}{-Prinsip/ akad } \\
-Mudharabah mutlaqah dan mudharabah \\
-Fuqayyadah \\
-Setoran & -Buku tabungan \\
-Penarikan & -ada penambahan \\
\hline 2. Bagi Hasil & -setiap saat memakai slip tabungan \\
-Sistem & -Revenue sharing \\
-Nisbah & -70:30 \\
-Syarat perolehan & -minimal saldo 50.000 \\
\hline 3. Distribusi & \\
\hline
\end{tabular}




\begin{tabular}{|l|l|}
\hline -Waktu & -Tiap akhir bulan \\
-Pembagian & -Penambahan di saldo tabungan nasabah \\
\hline
\end{tabular}

Sumber: data diperoleh dari hasil wawancara dan observasi dengan Ibu Ika karawan BPRS HIK Makassar.

Hasil penelitian yang di lakukan di BPRS HIK Makassar menunjukkan mekanisme perhitungan sistem bagi hasil yang digunakan menggunakan sistem revenue sharing dengan nisbah 70:30. Sistem revenue sharing berlaku pada pendapatan bank yang akan dibagikan dihitung berdasarkan pendapatan kotor. Pada BPRS HIK Makassar mekanisme sistem Revenue sharing yang digunakan dengan cara pembagian keuntungan pengelolaan dana yang dilakukan oleh Bank sebelum dipotong biaya operasional atau bagi hasil dihitung dari keuntungan kotor/total pendapatan dan menggunakan akad mudharabah mutlaqah dan mudharabah muqayyadah.

Jadi sistem revenue sharing di BPRS HIK Makassar sesuai dengan fatwa dewan syari'ah Nasional No:02/DSNMUI/IV/2000 tentang ketentuan umum tabungan berdasarkan Mudharabah:

a) Dalam transaksi ini nasabah bertindak sebagai shahibul maal atau pemilik dana, dan bank bertindak sebagai mudharib atau pengelola dana.

b) Bank tidak diperkenankan mengurangi nisbah keuntungan nasabah tanpa persetujuan yang bersangkutan.

\section{SIMPULAN}

Berdasarkan penelitian yang telah dilakukan serta hasil yang diperoleh seperti yang telah didiskripsikan pada bab-bab sebelumnya, dapat ditarik kesimpulan bahwa sistem transaksi tabungan Mudharabah di BPRS HIK Makassar menggunakan akad mudharabah mutlaqah dan mudharabah muqqayadah dan sistem bagi hasil yang diterapkan di BPRS HIK Makassar pada tabungan Mudharabah adalah mengacu pada prinsip revenue sharing artinya BPRS HIK Makassar mekanisme sistem Revenue sharing yang digunakan dengan cara pembagian keuntungan pengelolaan dana yang dilakukan oleh Bank sebelum dipotong biaya operasional atau bagi hasil dihitung dari keuntungan kotor/total pendapatan. 


\section{DAFTAR PUSTAKA}

Al-Qur'an dan Hadits.

Marzuki. 1986. Metodologi Riset. Yogyakarta: PT. Hanindita Offset.

Sugiyono, 2014. Metode penelitian Kuantitatif, kualitatif dan R\&D. Bandung: CV Alfabeta. 